\title{
CONTEXTUALIZAÇÃO DOS ASPECTOS SOCIOAMBIENTAIS SOBRE CATADORES DE MATERIAIS RECICLÁVEIS À LUZ DOS CONCEITOS DA EDUCAÇÃO AMBIENTAL CRÍTICA
}

\section{RODRIGO DOS PASSOS FARIA}

Instituto Federal de Educação, Ciência e Tecnologia do Rio de Janeiro E-mail: faria.rpf@gmail.com

\section{ALEXANDRE MAIA DO BOMFIM}

Instituto Federal de Educação, Ciência e Tecnologia do Rio de Janeiro E-mail: alexandre.bomfim@ifrj.edu.br

\section{MAYLTA BRANDÃO DOS ANJOS}

Instituto Federal de Educação, Ciência e Tecnologia do Rio de Janeiro E-mail: maylta.anjos@ifrj.edu.br

\section{GISELLE RôÇAS}

Instituto Federal de Educação, Ciência e Tecnologia do Rio de Janeiro E-mail: giselle.rocas@ifrj.edu.br

\section{RESUMO}

Este artigo se estrutura a partir do olhar que lançamos aos aspectos socioambientais analisados a partir de entrevistas de catadores de materiais recicláveis. Discutimos como esses se observam em relação ao ambiente e se veem dentro dele, contextualizando os aspectos socioambientais à luz dos conceitos da educação ambiental crítica, a partir do levantamento de relatos dos catadores entrevistados. Trata-se de uma pesquisa qualitativa que teve como participantes cinco catadores que estiveram presentes à VI Expo Catadores, São Paulo. Entre os resultados, observamos que eles têm, nessa atividade de trabalho, a única forma de garantir sobrevivência de suas famílias. Entretanto, a despeito da importância do trabalho, nos relatos desses sujeitos, o impacto econômico da reciclagem poucas vezes é adequadamente estimado, porque tido como atividade "sem estruturação", é a etapa essencial para fortalecimento da categoria, esta que se organiza em cooperativas de catadores de material reciclável e em associações.

\section{PALAVRAS-ChaVe:}

Educação Ambiental Crítica; Catadores de Material Reciclável; Aspectos Socioambientais. 
ABSTRACT

This article is structured from the look we have given to the socioenvironmental aspects analyzed from interviews with recyclable material collectors. We infer how these are observed concerning to the environment and also how they are seen within it, contextualizing the socioenvironmental aspects having regard to the concepts of critical environmental education, based on the surveying on the opinions and perceptions of the interviewed collectors. This is a qualitative research that had as participants five collectors who were present at the VI Expo Catadores, São Paulo. Among the results, we observed that they have, in this work activity, the only way to ensure survival for them and their families. However, in spite of the importance of work, in the speeches of these subjects, the economic impact of recycling is seldom adequately estimated, because considered as an activity "without structuring", is the essential step for strengthening the category, which is organized in cooperatives of waste collectors and associations.

\section{KEYWORDS:}

Critical Environmental Education; Recyclable Material Collectors; Socioenvironmental Aspects.

\section{INTRODUÇÃO}

Abordar sobre uma atividade que emerge de uma necessidade específica relacionada ao modo de vida contemporâneo, em sua utilização do meio ambiente, constitui-se em um desafio. Esse desafio é pontuado nas últimas décadas, quando observamos a forma como a humanidade se relacionou com a natureza ao longo de sua existência. Ao assumir essa questão como viés principal de análise, a pesquisa mostra a relevância da categoria "trabalho" e nas categorias que dela derivam, especialmente as que se relacionam às questões socioambientais.

No instante em que ligamos o holofote sobre uma parcela da população, considerada muitas vezes como "invisível", por muitas vezes ter seu trabalho tratado como subatividade, acabamos por mexer com valores, cultura e sentido político. Mexemos porque, na fragilidade de algumas profissões, essa é especialmente vista também como responsável pelo resíduo. Foi isso que nos incomodou e nos moveu a esse estudo. As questões socioambientais também emergem quando a discussão sobre o lixo vem à tona. Esse lixo que sai diariamente das casas, do comércio, das indústrias, sem que haja real conhecimento do seu trajeto e destino. Esse não reconhecimento também permite que as pessoas continuem consumindo sem uma 
reflexão adequada sobre o que necessitam e para que necessitam. Entretanto, sabese que os problemas oriundos do descarte inapropriado dos resíduos (OLIVEIRA e COSTA, 2008) geram desdobramentos múltiplos, de ordem social, ambiental e econômica. Porém há aqueles que sobrevivem do trabalho de fazerem esse lixo desaparecer. Discutiremos sobre estes sujeitos.

Nosso trabalho, em parte, baseia-se nesses pesquisadores que trabalham sobre a questão do trabalho, saúde, qualidade de vida dos Catadores de Materiais Recicláveis; porém, o que nos difere é a identificação do catador e de tal classe a partir de suas memórias (ALMEIDA e ANTUNES, 2005), tendo como base o avanço crítico e a formação de um movimento que permite ouvir a voz deste catador, associado ao nível de conhecimento de educação ambiental crítica, a partir de suas histórias, experiências, diálogos, manifestações, lutas..., dentro de uma situação política presente que favorece ou não tal classe.

Medeiros e Macedo (2006) denunciam a exclusão social e a "inclusão perversa" dos catadores nesse cenário. As autoras assinalam que a compreensão "de estar desempregado" significa para muitos a exclusão, mas rebatem perguntando se trabalhar sem um emprego estável, sem o reconhecimento pelos seus pares, pela Sociedade ou pelo Estado, caso de muitos catadores de lixo, é suficiente para se sentirem incluídos num contexto de reconhecimento profissional. Uns lixeiros e pedreiros têm esse reconhecimento. O primeiro possui a "segurança" de um emprego, já o segundo, quase sempre na informalidade e na situação de autônomo, também se sente um profissional. Então o que difere no caso dos catadores? As autoras afirmam que assumirmos tal discussão e colocarmos um holofote sobre ela

[...] levaria ao ofuscamento de artimanhas da exclusão social. Isso porque, por trás de formas aparentes de inclusão social, existem formas sutis de exclusão que conduzem a uma aparente inclusão, que camufla uma exclusão, entendida como inclusão perversa (MEDEIROS e MACEDO, 2006, p. 65). 
Como os catadores de materiais recicláveis percebem as questões socioambientais que circundam o seu trabalho cotidiano? Como a história oral e os seus relatos nos apresentam suas realidades sociais? Como podemos compreendê-las e contextualizá-las à luz dos conceitos da educação ambiental crítica? Ao assumirmos tais questões de norteamento da nossa pesquisa e pautados nas vozes de cinco catadores, trilhamos caminhos para compreender os aspectos socioambientais que circunscrevem o cotidiano desses sujeitos, os quais são considerados "periféricos", "indesejáveis", "invisíveis". É, portanto, a partir de seus relatos que buscamos a proposição de ações mais efetivas e respeitadoras desse coletivo, que trabalham "a favor de" e "para a" sociedade. De forma que, como objetivo central desse estudo é a contextualização dos aspectos sociais e ambientais a luz dos conceitos da educação ambiental crítica (GUIMARÃES, 2004), para os quais buscamos mapear a questão socioambiental nas observações e colocações dos catadores em relação ao seu entorno e ao seu trabalho. Propomos uma reflexão (ROÇAS e ANJOS, 2014) dessas percepções a luz de seus relatos, tomando por base o referencial teórico da Educação Ambiental Crítica (BOMFIM, 2011; 2015) relacionando a Educação (FREIRE, 2014) para desconstruirmos o senso comum (MARTINS, 2013) sobre a reciclagem e coleta seletiva como solução salvadora dos problemas dos resíduos sólidos.

\section{Nossos Entrevistados e Nosso Percurso Metodológico}

Esta pesquisa possui caráter qualitativo, pois se trata de um enfoque de investigação social, abordando aspectos da educação. Brandão (1999) e Brandão e Borges (2007) identificam que este tipo de pesquisa é direcionado a atores marginalizados e excluídos, sendo iniciada na realidade concreta (FREIRE, 1986), que tais atores pretendem mudar e gira em torno da problemática: a catação do lixo.

Ao partirmos da realidade concreta e da vida cotidiana dos participantes, tanto no seu aspecto individual quanto no aspecto e coletivo, a pesquisa ficou mais 
inteligível, e se mostrou a nós em suas diferentes dimensões e interações. As questões e os desafios surgidos ao longo do estudo nos fizeram acreditar que as ações sociais aliadas com as análises caminham rumo à educação ambiental crítica, podendo definir a necessidade e o estilo de procedimentos que são propostos pela pesquisa participante, em que é mais do que uma fonte de dados importantes, sendo capaz de contribuir ao revelar uma realidade concreta (BRANDÃO e BORGES, 2007).

A investigação foi realizada durante a 6a Expo Catadores, em São Paulo. Este evento foi uma iniciativa do Movimento Nacional da Catadores de Materiais Recicláveis (MNCR) junto com a Associação Nacional dos Carroceiros e Catadores de Materiais Recicláveis (ANCAT), em parceria com a Prefeitura de São Paulo e diversas empresas filiadas ao MNCR. Com cerca de 8.000 representantes de 26 estados brasileiros e 14 países. O evento teve a participação de 3.000 líderes de cooperativas e demonstrou a importância do Catador na economia.

O primeiro contato realizado antes do evento foi com a representante nacional do MNCR do Rio de Janeiro. Foi apresentada a pesquisa, os objetivos e a importância do resgate de memória ( $X X X X, X X X X)$. Todos os participantes assinaram um termo de livre consentimento livre (TCLE). Durante o evento foram abordados diversos representantes para a participação da pesquisa, dos quais obtivemos a anuência de cinco catadores que foram entrevistados (entrevista com roteiro semiestruturado).

Nossa primeira entrevistada (E1) faz parte da representação estadual do MNCR do Ceará. Mulher, mãe, negra, cerca de 55-60 anos de idade. De acordo com seu histórico no processo de vida na catação (cerca de 9 anos), ela era uma catadora de material reciclável em situação rua. Após contatos, entendeu o processo e se filiou a uma associação, onde é presidente e faz parte do ministério público como conselheira, defendendo tal classe. 
A segunda entrevistada (E2) faz parte da representação estadual do Paraná. Mulher, mãe, branca, cerca de 45-50 anos de idade. Seu processo na catação começa como moradora de rua. Depois de ser acolhida por uma atravessadora, ela amplia suas áreas de catação, ainda em situação de rua. Após período, recebe ajuda de uma instituição, onde começa a ter sua independência, tendo seu lar, mas ainda realizando catação em situação de rua. Foi se aproximando do movimento, na mesma condição, porém absorvendo experiências de outros catadores de outros estados. Participou da montagem da cooperativa (já dentro do MNRC), cerca de 23 anos.

Nossa terceira entrevistada (E3) faz parte da representação estadual da Paraíba. Mulher, negra, mãe, cerca de 45-50 anos de idade. Esta, por sua vez, teve a vivência do trabalho no lixão, tendo em seu relato, a tristeza de quem perde uma vida. O reaproveitamento de alimento e competição pela comida e materiais recicláveis entre seus companheiros e os animais que lá viviam. Inserida na catação certa de 25 anos. Recém representante do movimento (somente sete anos), mesmo não sendo cooperativada, foi reconhecida pelos companheiros de catação, os quais viram nela uma forma de liderança para representá-los.

A quarta entrevistada (E4) faz parte da representação estadual do Rio de Janeiro. Mulher, negra, mãe, cerca de 35-40 anos de idade. Teve sua inserção na catação ainda criança, vivendo na rua com sua família, também como pedinte e ambulante. Após aproximação de curso sobre políticas públicas, vem a estabelecer contato direto com demais catadores de situação de rua. Fortemente ligada a militância, pois seu exmarido foi representante do movimento durante uma das gestões anteriores. Neste período, ela se impõe como uma catadora de base, como cooperada, se torna liderança dos catadores de situação de rua, e presidente da cooperativa. Tendo sua inserção como representante, propriamente dita, há 5 anos, estadual e nacional pelo movimento. Ativista na Rio+20, ganha força e coragem no empoderamento das questões socioambientais. 
O último e único entrevistado (E5), possui cerca de 20 anos na catação. Homem, negro, certa de 35-40 anos de idade. Este apresenta sua vivência um pouco diferente que as demais entrevistadas. O mesmo passou por diversas profissões até chegar a catação. Pelo fechamento do Aterro de Nova Iguaçu foi para o lixão de Gramacho. Começou a organização como uma associação, e posteriormente, como cooperado. Enfatiza que "existe vida além do lixo", e apesar do ar poético ressalta a realidade concreta e cruel. Integra o Conselho Municipal de Meio Ambiente de Duque de Caxias, pautando sempre a inserção do catador nas temáticas discutidas.

Vale salientar, que grande parte dos representantes trocaram experiências com outros catadores de outros países, como Índia, Noruega, Holanda e países latinos americanos, tanto viajando para esses países ou passando por conferências no Brasil. Frisaram a importância da militância e do movimento na transição de suas vidas, pois possibilitou crescimento profissional e pessoal.

Vale dizer que fomos à análise das entrevistas por "interpretação livre", mas não de forma menos densa e rigorosa. A proposta de construir critérios/categorias que perpassam por autores pertinentes à Educação Ambiental Crítica (ainda que alguns não possam ser alocados integralmente nesse "lugar") é assumir que, das inúmeras possibilidades de coleta e análise sobre documentos e entrevistas, escolhemos uma (visível aos nossos leitores/interlocutores) para adentrar, refletir e buscar inferências. Após a transcrição das entrevistas, os documentos foram checados e contrapostos com as imagens gravadas durante a realização delas. Uma análise preliminar foi realizada, considerando os aspectos socioambientais identificados em seus relatos.

\section{NOSSOS ACHADOS}

A partir dos resultados obtidos nessas entrevistas, podemos notar tal parcela da população possui características muito similares, quando diz respeito às características do que esteja próximo do conceito de exclusão, tão dissimulado pelo discurso oficial. 
3.1 A CATEGORIA E O TRABALHO DO CATADOR: QUESTÕES INICIAIS

Os catadores em seu trabalho, que é essencialmente braçal, põem em movimento suas forças naturais a fim de apropriar-se de uma forma útil dos descartes materiais, estando nessa ação a força que nos leva pensar sobre os impactos ambientais e a utilização exaustiva e perversa do trabalho humano na sua mais absoluta precarização, levando em consideração os catadores em situação de rua e também os de cooperativa.

[...] e companheiras que trabalham 16, 18 horas por dia, iam pra rua, guardavam o material e a noite iam arrumar casa, fazer comida pra deixar pros filhos coisa e tal e nisso eu falei nós temos que mudar, as também muitos homens no meio, senhores que estavam na idade de se aposentar e estavam ali puxando carrinho ainda [...] (E2).

O trabalho realizado pelo catador ocupa um lugar central na vida dele, pois a catação é o meio de sobrevivência e o tempo de vida a ele dedicado assume uma parcela extensa do seu dia. Entretanto, não há proteção àqueles que não estão organizados em cooperativas, associações, entre outros, sendo uma vida insalubre e com várias ameaças a sua saúde física e mental (ANTUNES e ALVES, 2004); (MEDEIROS e MACÊDO, 2006)

Ainda que saibamos que Antunes (1995) discutia aspectos mais gerais sobre a precarização do trabalho, estabelecemos um paralelo sobre aquela análise e o trabalho do catador de lixo, já que apresenta um caráter precário das condições de trabalho nas captações que expoliam o corpo, com um processo de deterioração das relações de trabalho que é quase nada reconhecido, podendo provocar um sentimento de baixa estima e inutilidade no trabalhador, sentindo-se inferiorizado e humilhado em sua condição de trabalhador (DEJOURS, ABDOUCHELI e JAYET, 1994). À margem dos direitos trabalhistas, muitos situam-se nesse auto emprego disfarçados sob a falácia do "empreendedorismo" ou "ser patrão de a si mesmo", sendo essencial reforçar que eles estão de forma indireta ligados à indústria da reciclagem, alimentando a vida de 
empresas que lucram do tratamento dos resíduos sólidos, sem, contudo, terem acesso à seguridade social e aos direitos consolidados pela Consolidação das Leis Trabalhistas.

O trabalho é exaustivo e, como já dito, realizado pelos catadores em condições insalubres (GONÇALVES, 2004); (CAVALCANTE e SILVA, 2015), os quais são desprotegidos de segurança mínima e trabalham com resíduos que podem infectá-los com quaisquer tipos de zoonoses ou outro tipo de doença. Magera (2003), contribui para pensar essa relação de absoluta exploração ao dizer que além de estarem desprotegidos, exaurem corpo e alma ao puxarem os carrinhos com sua

tração humana, carregando por dia mais de duzentos quilos de lixo (quatro toneladas por mês), e percorrendo mais de vinte quilômetros por dia, sendo, no final, muitas vezes explorados pelos donos de depósitos de lixo (sucateiros) (MAGERA, 2003, p. 34).

Para Carmo (2005), os catadores, devido à sua parca educação formal, muitas vezes, não percebem o mecanismo de exploração ao qual estão submetidos pelas micro, pequenas e médias ações que acontecem em torno desse "negócio". Magera (2003) avalia que o "circuito da reciclagem" é um forte impedimento para que a categoria de catadores obtenha reconhecimento dessa atividade, visto que as grandes empresas, prefeituras e governos, ainda não colocam em prática a coleta seletiva, pois facilitaria a extração, separação, prensagem e venda dos materiais recicláveis, minimizando o esforço sobre-humano desta categoria de trabalho já reconhecida como ocupação profissional e referendado já em políticas públicas.

O crescimento da categoria está, sobretudo, relacionado a ampliação do consumo e dos descartáveis que tornam a vida mais prática, ainda que a praticidade gere maior passivo e menor sobrevida ao ambiente.

Ainda que os catadores estejam incluídos numa categoria que luta por seu espaço, estão excluídos pelo tipo de trabalho que se identifica na precariedade, na inadequação, na insalubridade e periculosidade que somada ao não reconhecimento pessoal, social, ambiental se localizam nos formatos mais sutis de exclusão, opressão 
social, violência e negligência. Os riscos sociais, a vulnerabilidade a que são expostos, a fragilidade à saúde, os desprezos e preconceitos sociais fazem parte do cotidiano desse que tem na informalidade de trabalho, sua baixíssima ou quase nula remuneração (DEJOURS, 1999).

\subsection{Aspectos Socioambientais: Nossa ANÁlise Sobre o OlHAr Deles}

As questões ambientais se exacerbam dia após dia, gerando impactos ambientais, afetando o padrão de consumo, impactando no planejamento financeiro das famílias e demais setores, entre outros desdobramentos (BORGES; SCHOLZ, e ROSA, 2014).

Eu acho que esta é importância maior na cadeia da reciclage [sic] é essa questão o catador ele em si fazer o recolhimento desses troços porque era isso que vinha acabano com rios, até os mares, a vegetação, vem acabando com tudo e a partir do momento que a gente ta recolhendo este material a gente ta evitando de este material ta indo [sic] pra algum espaço e poluindo, né? Pra destruir as matas, porque onde eu moro mesmo a prefeitura irresponsavelmente joga nas matas, joga junto onde tem nascente d'agua [...] (E3).

Considerando a amplitude dessas questões, diversas possibilidades e frentes de pesquisa e ação que a temática ambiental compreende, optamos focar as questões relacionadas ao descarte de resíduos sólidos. Especificamente, o entendimento acerca dos relatos de cinco catadores, os quais voluntariamente participaram desse estudo e possibilitaram-nos reflexões sobre as questões socioambientais que permeiam as suas realidades e vivências desse grupo social. Pautados na associação das categorias propostas por Reigota (1998), Loureiro, Layragues e Castro (2000), Loureiro (2007) entre outros, alcançamos as categorias emanadas a partir da análise das entrevistas, sendo elas: Visão Emancipatória, Visão Conservadora ou Comportamentalista, Visão Naturalista e Visão Antropocêntrica (Quadro 1). 
Quadro 1: Qual a percepção socioambiental acerca do MNCMR? Fonte: Elaborado pelos autores.

\begin{tabular}{|c|c|c|c|}
\hline Categoria & Síntese & Frequência & Extrato \\
\hline Visão Naturalista & $\begin{array}{l}\text { Concepção de ambiente } \\
\text { centrada nos aspectos } \\
\text { naturais, não considera o } \\
\text { ser humano parte do } \\
\text { contexto e sim um } \\
\text { observador }\end{array}$ & $\begin{array}{c}12 \\
\text { ocorrências }\end{array}$ & $\begin{array}{l}\text { "... - meu ex-marido, vem } \\
\text { ser o primeiro representante } \\
\text { lá pelo estado do Rio, } \\
\text { através do movimento..." } \\
\text { (E4) }\end{array}$ \\
\hline Visão Emancipatória & $\begin{array}{l}\text { Certeza de que somos seres } \\
\text { naturais e de que nos } \\
\text { realizamos e redefinimos } \\
\text { culturalmente o modo de } \\
\text { existir na natureza pela } \\
\text { própria dinâmica societária } \\
\text { na história da natureza }\end{array}$ & $\begin{array}{c}12 \\
\text { ocorrências }\end{array}$ & $\begin{array}{l}\text { “... - Eu comecei a trabalhar } \\
\text { com material reciclável com } \\
\text { 10, } 9 \text { anos eu comecei já } \\
\text { entendendo um pouco de } \\
\text { reciclagem, porque minha } \\
\text { história começou como..." } \\
\text { (E4) }\end{array}$ \\
\hline $\begin{array}{c}\text { Visão } \\
\text { Antropocêntrica }\end{array}$ & $\begin{array}{l}\text { Reconhece o meio ambiente } \\
\text { como recurso natural que é } \\
\text { útil à sobrevivência dos } \\
\text { humanos. }\end{array}$ & $\begin{array}{c}8 \\
\text { ocorrências }\end{array}$ & $\begin{array}{l}\text { “... } 15 \text { milhões de economia } \\
\text { de água, de energia e de } \\
\text { água. Quantas árvores } \\
\text { deixou de ser cortada? } \\
\text { Quantas quilos de bauxitas } \\
\text { foi deixado de ser tirado da } \\
\text { natureza? O movimento é } \\
\text { ciclo [...] o maior } \\
\text { responsável para a } \\
\text { diminuição do gás carbônico } \\
\text { do efeito estufa é o trabalho } \\
\text { dos catadores..." (E2) }\end{array}$ \\
\hline Visão Globalizante & $\begin{array}{l}\text { Globalizante agrega } \\
\text { concepções de meio } \\
\text { ambiente que considera a } \\
\text { relação entre a natureza e a } \\
\text { sociedade com seus } \\
\text { aspectos naturais, políticos, } \\
\text { sociais, econômicos, } \\
\text { filosóficos e culturais }\end{array}$ & $\begin{array}{c}8 \\
\text { ocorrências }\end{array}$ & $\begin{array}{l}\text { "... seu material dentro e } \\
\text { vender prum [sic] deposeiro } \\
\text { [sic], pra uma associação, } \\
\text { seja o que for, né! Dalí ele } \\
\text { tira o sustento dele pra se } \\
\text { alimentar, ou para comprar } \\
\text { o que ele bem quer ou o que } \\
\text { ele bem entende, né" (E1). }\end{array}$ \\
\hline $\begin{array}{l}\text { Visão Conservadora } \\
\text { ou } \\
\text { Comportamentalista }\end{array}$ & $\begin{array}{l}\text { Convicção de que houve um } \\
\text { afastamento de nossa } \\
\text { espécie de relações } \\
\text { adequadas, idealmente } \\
\text { concebidas como inerentes } \\
\text { aos sistemas ditos naturais, }\end{array}$ & $\begin{array}{c}6 \\
\text { ocorrências }\end{array}$ & $\begin{array}{l}\text { "... - E aí na rua às vezes se } \\
\text { batesse com algum } \\
\text { conhecido aí tinha aquela } \\
\text { questão da vergonha" (E3). }\end{array}$ \\
\hline
\end{tabular}




\begin{tabular}{|c|l|c|l|}
\hline & $\begin{array}{l}\text { sendo necessário o retorno } \\
\text { a esta condição natural pela } \\
\text { cópia das relações } \\
\text { ecológicas. }\end{array}$ & & 2 \\
\hline Visão Religiosa & $\begin{array}{l}\text { A percepção do papel } \\
\text { sagrado e divino da } \\
\text { natureza. Quase intocado. }\end{array}$ & $\begin{array}{l}\text { "... e eu disse: - vou orar que } \\
\text { vai dar tudo certo. E eu } \\
\text { orava, e Deus dava vitória" } \\
\text { (E4). }\end{array}$ \\
\hline
\end{tabular}

Ao analisarmos os relatos dos catadores sobre o entendimento deles acerca dos aspectos socioambientais, aparecem fortemente as categorias que englobam as visões naturalista, antropocêntrica, emancipatória: onde demonstra a relação do homem com a natureza, a preocupação em conservar os recursos naturais, trazendo à tona o papel do mesmo como agente mitigador de danos ao meio ambiente e uma economia verde para a sociedade, além de se identificarem como parte da natureza e não só utilizadores e observadores dos recursos naturais para os bens pessoais. Entendem que todas as ações antrópicas implicam num dano ao meio ambiente, e que realizam um grande papel na melhoria do mesmo. As categorias que englobem as visões conservadora ou comportamentalista, religiosa e globalizante: percebemos como os catadores consideram a relação entre a natureza e a sociedade, tanto nos aspectos naturais, políticos, sociais, econômicos, filosóficos e culturais, pois os mesmo adquirem conhecimento ao longa da sua trajetória, modificando suas ações e ideologias durante o desenvolvimento do seu trabalho, além da troca de experiências com outros companheiros de trabalho de diversos outros estado e países. Entendem, que fazem parte do processo de reciclagem até a etapa final de venda desses materiais reciclados, tendo sem suas concepções que fazem parte das relações ecológicas (um processo cíclico). Além disso, encontram num ser divino, que oferece tais recursos naturais para a realização do trabalho, e que tal força divina os ajuda durante cada etapa de suas vidas, contribuindo para o êxito e eficiência no trabalho desenvolvido. Na concepção 
naturalista, poucos trechos apontam a segregação homem-natureza, pois todos entendem que fazem parte da mesma e que precisam conservá-la. Porém, como demonstramos acima todas as categorias seguem um direcionamento em comum: o meio ambiente. Neste sentido destacamos que a visão religiosa, a qual compreende a percepção do papel sagrado e divino da natureza foi a menos comum, ainda que há a ocorrência de mais de uma visão nos relatos dos entrevistados, onde o ser divino é bondoso e os ajudam no processo laboral e de suas vidas pessoais. Tem como tal ser divino a ideologia de que ele está presente no cotidiano das suas vidas, os ajudando e dando força neste trabalho árduo, onde eles têm a consciência que tudo que na natureza foi tal ser divino que proporcionou para a execução de seus trabalhos.

\subsection{A InVISIBILIDAdE QUE SE TRAdUZ EM MILITÂNCIA: A Voz QUe Não SE CALA}

Nos relatos dos entrevistados, percebemos que os mesmos, por mais que tenham passado por momentos de constrangimento ou humilhação, a catação traz protagonismos e identificação de tal classe como forma de trabalho e envolvimento socioambiental. Lógico que analisamos, não só a partir dos relatos, mas pelos recortes teóricos como o catador ainda tem uma invisibilidade na sociedade.

O MNCR é um órgão de potência no Brasil que traz à tona a situação do catador em cada estado e milita a favor do reconhecimento e visibilidade do trabalho e da classe para melhoria e bem-estar (NASCIMENTO; MARQUES; ALMEIDA e NASCIMENTO, 2006) do catador, mas não só isto, levando em consideração a melhoria do meio ambiente. Podemos também analisar a percepção de Santos (2014), exrepresentante do MNCR do Rio de Janeiro, que destaca em seu livro a dificuldade de "nascer no lixo" e sobreviver dele. Tais experiências o levaram ao documentário "Lixo Extraordinário ${ }^{1 \prime}$, mostrando uma estética de tristeza e beleza cinematográfica e o 
desespero de ser reconhecido como catador, tendo respeito, igualdade e identidade

igual a de qualquer outro cidadão.

[...] aí eu entrei mesmo pra fazer parte da militância, na coordenação do movimento, em 2000. Eu fiz participação do primeiro encontro latino americano, que foi em Caxias do Sul, que meu ex-marido era representante, aí fui conduzindo ônibus, a caravana, aquela coisa. Mas militante mesmo, foi em 2005 [...] (E4).

E no que tange a questão da "invisibilidade" social, observamos no relato de uma das catadoras que há muito mais a ser feito do ponto de vista das políticas públicas.

"Eu não sei como que pode os governantes desse país não verem ainda sabe, nós queremos tão pouco, queremos só paguem por um serviço que nós prestamos, que o nosso serviço é de utilidade física, estamos defendendo o meio ambiente, o trabalho e renda, nós estamos tirando pessoas da linha da pobreza, tirando da rua. Será que é tão difícil reconhecer um trabalho, como um grupo de teatro colocou ali, um trabalho de formiguinha? E o nosso trabalho se você for pesquisa e ver, a formiga é o bicho mais organizado que tem. Ela tem o seu próprio cemitério, tem seu próprio hospital, maternidade, ela trabalha no verão pra comer no inverno, então eu sempre digo pros catadores vamos se transformar nesse grande formigueiro, claro que o pé grande vai pôr o pé lá, ele vai machucar, vai matar, mas ele vai levar umas boas mordidas e ele nunca mais vai por o pé lá e então assim é isso que a gente quer sabe, se hoje eu tenho condições de ganhar mil reais, eu quero que o meu companheiro ganhe mil reais" (E2).

No quadro 2, apresentamos categorias que emergiram ao longo da nossa análise. No entanto, vale salientar que só utilizamos as categorias de Reigota (1995) e Loureiro, Layargues e Castro (2000) para a Quadro 1.

Quadro 2: Como começou a trabalhar na catação? Fonte: Elaborado pelos autores.

\begin{tabular}{|c|l|c|c|}
\hline Categoria & \multicolumn{1}{|c|}{ Síntese } & Frequência & \multicolumn{1}{c|}{ Extrato } \\
\hline Falta de opção & $\begin{array}{l}\text { Concepção de que } \\
\text { devido as situações } \\
\text { impostas pela sociedade, } \\
\text { o referente não se vê } \\
\text { com opções para serviço } \\
\text { e, portanto, só lhe restou } \\
\text { apenas uma opção. }\end{array}$ & 2 ocorrências & $\begin{array}{l}\text { "Eu comecei a trabalhar como } \\
\text { catador por falta de opção, } \\
\text { né!" (E5). }\end{array}$ \\
\hline Necessidade & $\begin{array}{l}\text { O referente entende que } \\
\text { sofre privações dos bens }\end{array}$ & 2 ocorrências & $\begin{array}{l}\text { "-Então, foi naquele período } \\
\text { que tava, não tinha emprego }\end{array}$ \\
\hline
\end{tabular}




\begin{tabular}{|c|c|c|c|}
\hline 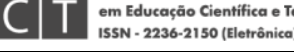 & & \multicolumn{2}{|c|}{ Revista Eletrônica DECT, Vitória (ES), v. 9, n. 01, p. 196-218, 2019} \\
\hline & $\begin{array}{l}\text { necessários para se } \\
\text { manter, levando-o a } \\
\text { procurar um meio de } \\
\text { retorno financeiro que } \\
\text { não haja qualificações } \\
\text { para que seja executado. }\end{array}$ & & $\begin{array}{l}\text { mesmo, era muito difícil, então } \\
\text { assim, com dois filhos } \\
\text { pequenos e grávida já do } \\
\text { quarto, então assim, o que me } \\
\text { sobrou foi a catação e aí eu } \\
\text { conheci uma dona do que a } \\
\text { gente chama de atravessador, } \\
\text { ferro velho e ela me ofereceu } \\
\text { pra mim um barraco, pra mim } \\
\text { morar com meus filhos, e aí eu } \\
\text { comecei nisso" (E2). }\end{array}$ \\
\hline $\begin{array}{c}\text { Consequências } \\
\text { da vida }\end{array}$ & $\begin{array}{l}\text { Fatos que ocorreram } \\
\text { durante a vida, que } \\
\text { levaram o referente a } \\
\text { executar tal atividade. }\end{array}$ & 3 ocorrências & $\begin{array}{l}\text { "-Eu tinha um filho que era } \\
\text { usuário de droga... Aí eu peguei } \\
\text { um complexo comigo de não } \\
\text { trabalhar mais pra ninguém, } \\
\text { por que fiquei com medo" (E1) }\end{array}$ \\
\hline
\end{tabular}

Quando perguntados sobre a inserção deles no mundo da catação, observamos no relato que a falta de opção, necessidade as consequências da vida são elementos fortes que os levaram a tal profissão (quadro 2). Ainda que possamos associar as três categorias, percebemos que todos tiveram situações muito similares em períodos de tempo diferentes: falta de opção, necessidade (por não ter quem a ajudar), inserção durante a infância são as mais apontadas dentro dos cinco entrevistados.

Podemos analisar a partir do relato da segunda entrevistada que integra um grupo de apoio de mulheres militantes do movimento, informando que cerca de $85 \%$ dos catadores do Brasil são mulheres. E Freire (2014), indica a rejeição de discriminação contra classe, gêneros, raças, religiões, etc. Onde o empoderamento durante o aprendizado social/ não formal se faz necessário para crescimento de conhecimento. Ou seja, as mulheres são fortes e detentoras de conhecimento popular e científico, nesta situação, neste grupo de pesquisa. "Há uma pedagogicidade indiscutível na materialidade do espaço" $(2014,45)$.

Contudo, ao entrarem para o MNCR essa ausência de opções começa a diminuir. A "ausência de luz ao final do túnel" em que viviam é substituída por um movimento 
de pertencimento. Passam a ser visto pela sociedade, ganham uma ocupação frente ao ministério do trabalho. A invisibilidade é então substituída por militância e engajamento (ZIGLIO, JESUS e SOUZA, 2016) conforme podemos ver na Quadro 3 abaixo.

Quadro 3: Com se dá o papel de militância no MNCMR? Fonte: Elaborado pelos autores.

\begin{tabular}{|c|c|c|c|}
\hline Categoria & Síntese & Frequência & Extrato \\
\hline $\begin{array}{l}\text { Espírito de } \\
\text { liderança }\end{array}$ & $\begin{array}{l}\text { De uma forma sintética, } \\
\text { liderar significa dirigir ou } \\
\text { comandar, incentivar } \\
\text { e motivar os membros } \\
\text { da organização por forma a } \\
\text { criar as condições necessárias } \\
\text { para que estes contribuam, } \\
\text { voluntariamente e da melhor } \\
\text { forma possível, para os } \\
\text { interesses da organização, } \\
\text { nomeadamente para que esta } \\
\text { atinja os seus objetivos. }\end{array}$ & $\begin{array}{c}3 \\
\text { ocorrências }\end{array}$ & $\begin{array}{l}\text { "Rapaz, é porque eu, em } \\
\text { toda vida eu gostei, assim, } \\
\text { toda vida eu gostei de ser } \\
\text { assim império, sabe? [...] } \\
\text { Assim, aquela agitação, } \\
\text { aquela coisa, eu gosto das } \\
\text { coisas direitinho, na linha, } \\
\text { não sabe? Acho que, acho } \\
\text { que foi isso, as pessoas } \\
\text { viram em mim, me jogaram } \\
\text { mais um cargo como } \\
\text { presidente..." (E1) }\end{array}$ \\
\hline Hierarquicamente & $\begin{array}{l}\text { É ordem que existe de forma } \\
\text { a priorizar um membro, } \\
\text { poderes, categorias, patentes } \\
\text { e dignidades de suas } \\
\text { organizações. }\end{array}$ & $\begin{array}{c}1 \\
\text { ocorrência }\end{array}$ & $\begin{array}{l}\text { "O meu ex-marido, vem ser } \\
\text { o primeiro representante lá } \\
\text { pelo estado do Rio, através } \\
\text { do movimento. Ele começou } \\
\text { mesmo a fundação da luta } \\
\text { desse movimento..., Aí eu } \\
\text { passei a trabalhar com os } \\
\text { catadores sem situação de } \\
\text { rua, pra apoiar eles. Hoje } \\
\text { me tornei, de lá pra cá, uma } \\
\text { liderança dos catadores em } \\
\text { situação de rua lá no Rio de } \\
\text { Janeiro, né!" (E4) }\end{array}$ \\
\hline Democraticamente & $\begin{array}{l}\text { É de maneira democrática; } \\
\text { através de algum mecanismo } \\
\text { de indicação coletiva. }\end{array}$ & $\begin{array}{c}1 \\
\text { ocorrência }\end{array}$ & $\begin{array}{l}\text { "Mas aí o pessoal, os } \\
\text { catadores, do meu Estado } \\
\text { me viram como uma } \\
\text { liderança. De repente assim } \\
\text { o companheiro lá fez uma } \\
\text { campanha pra mim na } \\
\text { doida e dei por fé o povo me } \\
\text { elegero [sic]" (E3) }\end{array}$ \\
\hline
\end{tabular}


No quadro 3 podemos observar que a militância surgiu de forma distinta para cada um deles. Uma seguindo os passos do ex-marido, outra sendo eleita, mesmo não fazendo parte de uma cooperativa, outra fazendo parte de uma associação. Tais analisas demonstraram que houve democracia ao elegerem cada uma delas; uma seguindo os passos do ex-marido, mesmo sendo algo hierárquico, também foi eleita democraticamente e todas demonstrando algum nível de liderança.

Após entrarem no movimento, a visibilidade de cada um foi despontada. Hoje, percebemos que duas, dos cinco entrevistados são acionados para discussões de políticas públicas com ministros e governantes locais e internacionais, além de darem palestras em universidades nacionais e internacionais, a partir das suas histórias de vida. Visto por esse ângulo, tal visibilidade não se deu somente com os entrevistados, mas em outros trabalhos acadêmicos e cinematográficos, como por exemplo, o documentário "Estamira"2; o documentário "A Margem do Lixo"3"; o livro como álbum fotográfico "Catadores"; o livro "Catadores de Materiais Recicláveis: um encontro Nacional"5"; e o mais recente documentário "Catadores de História ${ }^{6 "}$ realizado em parceria com o MNCR apresentando outras perspectivas e histórias de superação. Mostrando que já existe uma parcela visível a comunidade. Neste último documentário a cineasta diz:

"Durante todo o processo de filmagens, o que mais ouvimos foi sobre a importância de catadoras e catadores serem vistas(as), serem reconhecidas(os). Essa é a importância da participação do filme em festivais: tornar visível o universo da catação", declarou Tania Quaresma, diretora do filme (MNCR, 2016).

Mas a luta por reconhecimento em todo território não para nisso:

"Nunca poderia imaginar que nós poderíamos trazer às telas a história daqueles que muitas vezes não são lembrados, são esquecidos. Aqueles que

\footnotetext{
2 Produzido por José Padilha, no ano de 2005.

3 Produzido por Evaldo Mocarzel, no ano de 2008.

${ }^{4}$ Produzido pelo fotógrafo baiano, Aristides Alves, no ano de 2015.

${ }^{5}$ Produzido e Organizado por JAQUETTO, Bruna Cristina Pereira e GOES, Fernanda Lira, em 2016.

${ }^{6}$ Produzido por Tânia Quaresma, no ano de 2016.
} 
estão ali, mas são invisíveis, aqueles que fazem um trabalho importante, muito mais do que qualquer doutor, um trabalho realmente para a natureza", declarou Alex Cardoso, que integrou a equipe de produção como Assistentes de Direção (Representante Regional e Nacional do MNCR de Porto Alegre (MNCR, 2016).

Até a Política Nacional de Resíduos Sólidos e a Política Nacional de Saneamento Básico serem implementado em todo território nacional, haverá manifestações e militâncias.

\section{CONSIDERAÇÕES FINAIS}

Retomamos as perguntas já apontadas anteriormente: Como os catadores de materiais recicláveis percebem as questões socioambientais que circundam o seu trabalho cotidiano? Como a história oral e seus relatos nos apresentam suas realidades sociais? Como podemos compreendê-las e contextualizá-las à luz dos conceitos da educação ambiental crítica? Percebemos que o processo de invisibilidade passa para uma etapa de protagonismo, de militância, liderança e senso crítico das questões socioambientais e das políticas públicas que as pertence. Contextualizando a interface ambiental de forma crítica. Que através das suas histórias orais e memórias, houve um conhecimento e reconhecimento enquanto indivíduos e coletivo, e não só detentoras do saber popular, mas passam a somar, através de suas experiências saberes científicos através da dialogicidade crítica em todos os aspectos que os cercam, principalmente as questões socioambientais.

Propomos, então, uma reflexão dessas percepções à luz de seus relato, tomando por base o referencial teórico da educação ambiental crítica, tais como: Guimarães (2004), Bomfim (2011 e 2015), Maia et al. (2013) e Bomfim et al. (2015) para desconstruirmos o senso comum sobre a reciclagem, como solução salvadora dos problemas dos resíduos sólidos e aprofundar a discussão acerca do modelo de produção que a promoveu. 
Pode-se considerar que os objetivos da pesquisa não se esgotam nessa análise, uma vez que o assunto é amplo e só foi possível levantar questões sobre os catadores de materiais recicláveis no que entendemos por socioambiental, muito há ainda que ser explorado no breve recorte que traçamos aqui. Há que se explorar muito mais as relações de trabalho que envolve essa categoria para se destacar nelas os temas socioambientais que possam estar presentes.

Dentre as alternativas para a questão que permeia os resíduos urbano, a redução e a reutilização deveriam vir antes da reciclagem, entretanto é essa última que se configura como importante elemento, pois possibilita o reaproveitamento de materiais descartados novamente ao circuito produtivo alimentando a indústria e mantendo os códigos de relação de trabalho do mundo capitalista.

Há que se pensar que os catadores são trabalhadores que desempenham um papel preponderante e mitigador para pensarmos passado, presente e futuro de nossas ações no mundo e para o mundo. Nessa relação estão explícitas as condições perversas dada a essa categoria e trabalho desempenhado, mostrando e exemplificando-nos que a dialética inclusão está camuflada num discurso que busca esconder a exclusão dos direitos que os catadores estão submetidos. Isso permite compreender o conceito de inclusão no seu avesso, na dissimulação tão presente e que nos torna cativo daquilo que não nosso, nos prende.

\section{AgRADECIMENTOS}

Agradecemos aos alunos de iniciação científica XXXXXX (2015) e XXXXXX (2016) que auxiliaram na coleta e tabulação dos dados. Ao CNPq pelas bolsas PIBIC, ao XXXX pelo fomento via edital XXXXXXXX. 


\section{REFERÊNCIAS}

ALMEIDA, Sandro Henrique Vieira de e ANTUNES, Mitsuko Makino. A Teoria Vigotskiana Sobre Memória: Possíveis Implicações para a Educação. Anais da $28^{a}$ Reunião Anual Da ANPED. 2005.

ANTUNES, Ricardo. Adeus ao trabalho? Ensaio sobre as metamorfoses e a centralidade do mundo do trabalho. Campinas, SP: Cortez. 1995.

ANTUNES, Ricardo e ALVES, Giovanni. As Mutações no Mundo do Trabalho na Era da Mundialização do Capital. Educ. Soc., Campinas, vol. 25, n. 87, p. 335-351, maio/ago. 2004. Disponível em: <http://www.scielo.br/pdf/es/v25n87/21460.pdf>. Acesso em: 23.03.2018.

BOMFIM, Alexandre Maia do. Trabalho, meio ambiente e educação: apontamentos à educação ambiental a partir da filosofia da práxis. Revista Labor n.5, v.1, 2011. Disponível em: <http://www.repositorio.ufc.br/handle/riufc/6673>. Acessado em: fev/ 2016.

BOMFIM, Alexandre Maia do. A desconstrução de certa educação ambiental. Revista Ciências \& Ideias. Editorial: Temático Educação Ambiental. vol. 6, n. 1, p. 1-2, jan/jun: 2015. Disponível em: <http://revistascientificas.ifrj.edu.br:8080/revista/index.php/ reci/article/view/466/308 > . Acessado em: fev/ 2016.

BOMFIM, Alexandre Maia do; TRINDADE, Margarete Alvarenga Viana Mota; SILVA, Flora Gomes de Oliveira da e OLIVEIRA, Thiago da Silva. A questão ambiental na educação básica. (Orgs), Rio de Janeiro: Publit, 2015.

BORGES, Maria de Lourdes; SCHOLZ, Robinson Henrique e ROSA, Graciema de Fátima da. Identidade, aprendizagem e protagonismo social: sentindo do trabalho para os sujeitos recicladores. Outra Economía, vol. 8, n. 14, enero-junio, 2014.

BRANDÃO, Carlos Rodrigues. Repensando a pesquisa participante. (Org.). São Paulo: Brasiliense, 1999

BRANDÃO, Carlos Rodrigues e BORGES, Maristela Correa. A pesquisa participante: um momento da educação popular. Rev. Ed. Popular, Uberlândia, v. 6, p.51-62. jan./dez. 2007. Disponível em: <http://www.seer.ufu.br/index.php/reveducpop/article/view File/19988/10662>. Acessado em: fev/ 2016.

BRASIL. Ministério do Meio Ambiente. Lei no 12.305/10. Comitê Interministerial para Inclusão Social e Econômica dos Catadores de Materiais Reutilizáveis e Recicláveis (CIISC), Decreto no 7.405/ 2010. Publicado no DOU de 3.8.2010.

CARMO, Maria Scarlet do. A semântica "negativa" do lixo como fator "positivo" à sobrevivência da Catação - Estudo de caso sobre a associação dos recicladores do Rio 
de Janeiro. Anais. Encontro Nacional da Associação Nacional de Pós-graduação em Pesquisa em Administração. ENANPAD, Brasília - DF. 2005.

CAVALCANTE, Lívia Poliana Santana e SILVA, Monica Maria Pereira da. Influência da organização de catadores de materiais recicláveis em associação para a melhoria da saúde e minimização de impactos socioambientais. REMOA - v.14, n.1, jan.-abr. 2015, p.01-13. Disponível em <https://periodicos.ufsm.br/remoa/article/download/15010/ pdf>. Acessado em: mar/ 2018.

DEJOURS, Christophe. A banalização da injustiça social. Rio de Janeiro, RJ: Editora da FGV. 1999.

DEJOURS, Christophe; ABDOUCHELI, Elisabeth e JAYET, Christian. Psicodinâmica do trabalho: contribuições da escola dejouriana à análise da relação prazer, sofrimento e trabalho. São Paulo, SP: Atlas. 1994.

FREIRE, Paulo. Criando métodos de pesquisa alternativa: aprendendo a fazê-la melhor através da ação. (Org). Carlos Rodrigues Brandão. 6a edição. Pesquisa Participante. Editora Brasiliense. p. 34-41. 1986.

FREIRE, Paulo. Pedagogia da autonomia: saberes necessários à prática educativa. 48a edição. Rio de Janeiro: Paz e Terra, 2014.

GONÇALVES, Raquel de Souza. Catadores de materiais recicláveis: trajetórias de vida, trabalho e saúde. Dissertação de Mestrado. Rio de Janeiro, FIOCRUZ/ENSP, 2004. Disponível em: <https://www.arca.fiocruz.br/bitstream/icict/5344/2/625.pdf>. Acessado em: jun/ 2017.

GUIMARÃES, Mauro. Educação Ambiental Crítica. In: Philippe Pomier Layrargues. (Org.). Identidade da Educação Ambiental Brasileira. 1a ed. Brasília: Ministério do Meio Ambiente, 2004.

LOUREIRO, Carlos Frederico Bernardo. (Org.). A questão ambiental no pensamento crítico: natureza, trabalho e educação. Rio de Janeiro: Quartet, 2007.

LOUREIRO, Carlos Frederico Bernardo. LAYARARGUES, Philippe Pomier e CASTRO, Ronaldo Souza de (Orgs.). Teoria Social e Questão Ambiental: Pressupostos para uma Práxis Crítica em Educação Ambiental. Sociedade e Meio ambiente: A Educação Ambiental em Debate. São Paulo, Cortez, 2000.

MAGERA, Márcio. Os empresários do lixo: um paradoxo da modernidade. Campinas, SP: Átomo. 2003.

MAIA, Hérika Juliana Linhares; CAVALCANTE, Lívia Poliana Santana; OLIVEIRA, Alinne Gurjão de e SILVA, Monica Maria Pereira da. Educação ambiental: instrumento de mudança de percepção ambiental de catadores de materiais recicláveis organizados em associação, Campina Grande/ PB. Revista Monografias Ambientais - REMOA - v. 
13n. 13, p. 2797 - 2806, Dez. 2013. Disponível em: <https://periodicos.ufsm.br/ remoa/article/view/9630/pdf>. Acessado em: jun/2017.

MARTINS, Edneia. Conhecimento científico e senso comum: ensino de ciências na educação de jovens e adultos (EJA) para a formação crítica. In: III Seminário Nacional de Formação Continuada de Professores e III Mostra de Experiências e Vivências Pedagógicas, Cascavel. UNIOESTE, 2013. v. 3. p. 1-12. Disponível em: <http://cacphp.unioeste.br/eventos/serprof/anais/trabalhos/artigo/artigo/32.pdf>. Acessado em: fev/ 2016.

MEDEIROS, Luiza Ferreira Rezende de; MACÊDO, Kátia Barbosa. Catador de Material Reciclável: Uma Profissão para além da Sobrevivência? Psicologia e Sociedade, vol. 18, n 2, pág 62-71. 2006. Disponível em: <http://www.scielo.br/pdf/psoc/v18n2/08.pdf>. Acessado em: jun/ 2017.

MNRC (Brasil). Documentário: 'Catadores de História' recebe três prêmios no Festival de Brasília. Texto redigido pelo Movimento Nacional dos Catadores de Materiais Recicláveis. Publicado e modificado em 28/09/2016. Disponível em: <http://www. mncr.org.br/noticias/noticias-regionais/filme-catadores-de-historia-recebe-trespremios-no-festival-de-brasilia>. Acesso em: jun/2018.

MNRC (Brasil). Documentário: 'À Margem do lixo' recebe diversos prêmios. Texto redigido pelo Movimento Nacional dos Catadores de Materiais Recicláveis. Publicado em 08/12/2008 e modificado em 09/02/2012. Disponível em: < http://www.mncr.org. $\mathrm{br} /$ noticias/noticias-regionais/filme-sobre-catadores-esta-entre-6-indicados-apremiacao>. Acesso em: jun/2018.

NASCIMENTO, Marta Leite da Silva; MARQUES, André Luís de Paula; ALMEIDA, Ana Marina Lourenço Pereira de; NASCIMENTO, Nazem. De catador de lixo a agente ambiental: educação ambiental na qualidade de vida. O Mundo da Saúde. São Paulo: 2006: out/dez 30 (4): 581-587.

OLIVEIRA, Luiz Cézar Suéke de e COSTA Pierre Alves. A problemática socioambiental do lixo domiciliar urbano em Guarapuava - PR. 2008. Orientação de outra natureza. (Programa de Desenvolvimento Educacional (PDE) - PR) - Universidade Estadual do Centro-Oeste, Secretaria de Estado da Educação do PR. Orientador: Pierre Alves Costa. Disponível em: <http://www.diaadiaeducacao.pr.gov.br/portals/pde/arquivos/709-4. pdf>. Acesso em: jun/ 2015.

REIGOTA, Marcos. Desafios à educação ambiental escolar. In: JACOBI, P. et al. (orgs.). Educação, meio ambiente e cidadania: reflexões e experiências. São Paulo: SMA, 1998. p.43-50.

REIGOTA, Marcos. Meio Ambiente e Representação Social. São Paulo: Cortez, 1995. SANTOS, Tião. Tião do Lixão ao Oscar. São Paulo: Editora Leya, 2014. 
ZIGLIO, Luciana; JESUS, Michael Dias de e SOUZA, Etelvino dos Santos. A Geografia da

Invisibilidade dos Catadores de Materiais Recicláveis: Lixo como Luxo. Revista Eletrônica UNIESP Centro Novo, 2016. Disponível em: < https://www.researchgate.net /publication/294891794_A_GEOGRAFIA_DA_INVISIBILIDADE_DOS_CATADORES_DE_ MATERIAIS_RECICLAVEIS_LIXO_COMO_LUXO>. Acesso em: 09/06/2018. 